\title{
Endoscopic findings of small-intestinal Epstein-Barr virus-associated T-cell lymphoproliferative disorder
}

A 71-year-old woman was admitted to our hospital in October 2009 with a 3-month history of severe diarrhea and weight loss of $5 \mathrm{~kg}$ with hypoalbuminemia. Computed

tomography showed diffusely thickened small-intestinal wall and intra-abdominal lymphadenopathy. Capsule endoscopy revealed flattened villi throughout the small

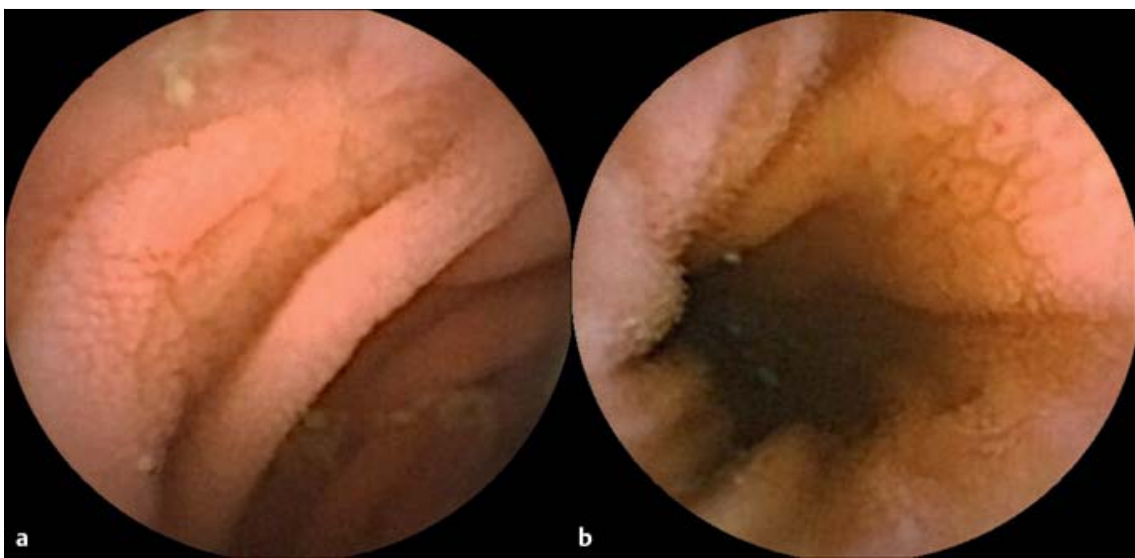

Fig. 1 Capsule endoscopy findings in the small intestine. a Villous atrophy and flattening were found throughout the small intestine. $\mathbf{b}$ Red spots were observed in the lower small intestine.
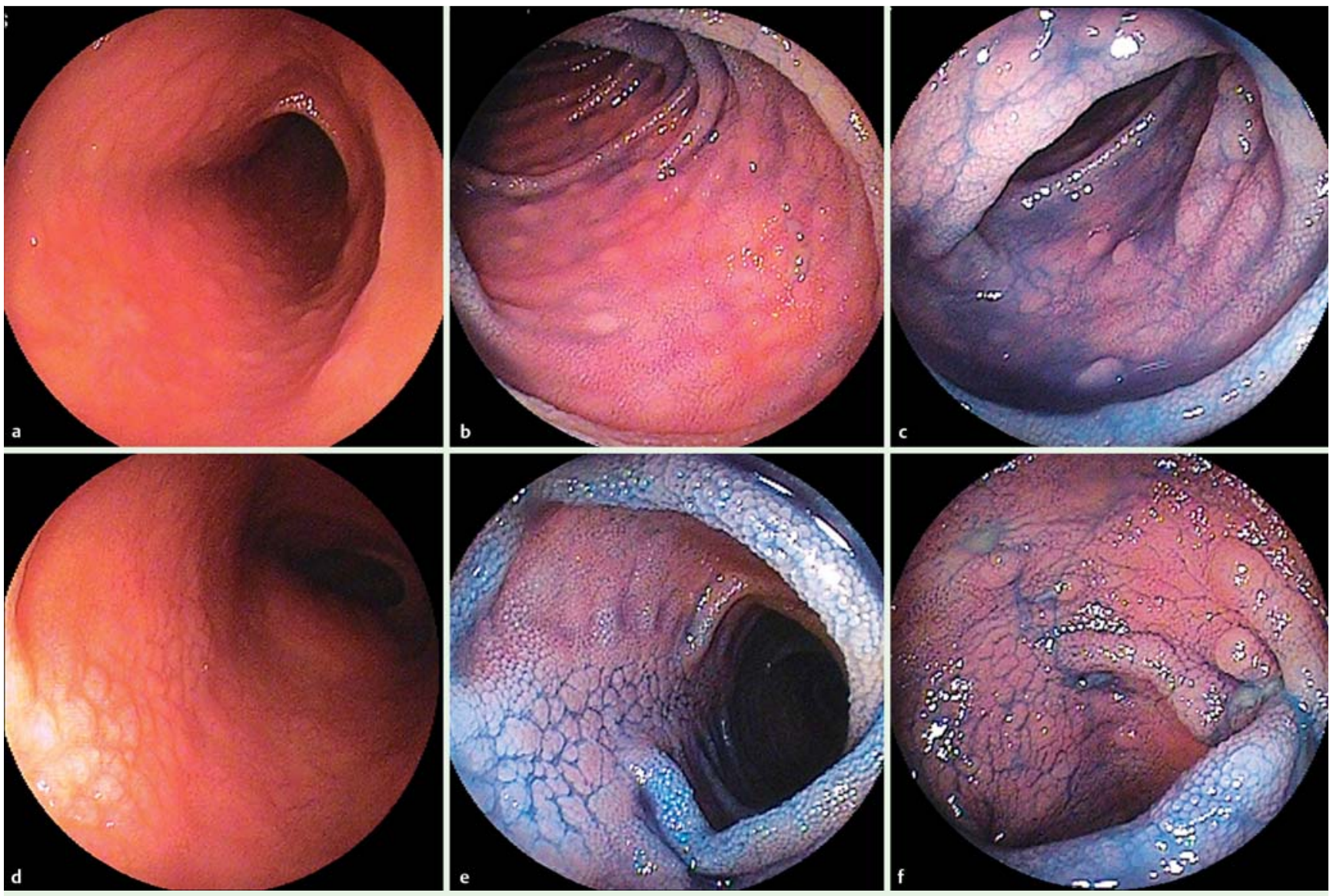

Fig. 2 a-f Double-balloon endoscopy findings in the small intestine. a - c Small-intestinal villi were diffusely flattened and atrophic. $\mathbf{d}$ - $\mathbf{f}$ Peyer's patches with swollen lymphoid follicles were clearly visible. 


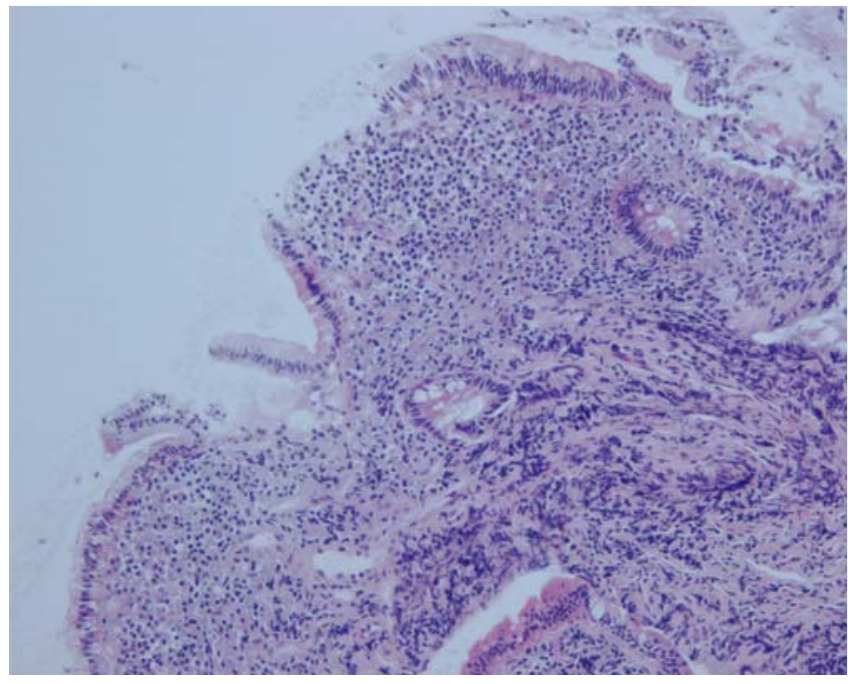

Fig. 3 Small-intestina mucosa; hematoxylin and eosin staining. Villous structures are tentatively suggestive of celiac disease. Many lymphocytes without neoplastic changes were seen beneath the epithelial layer.

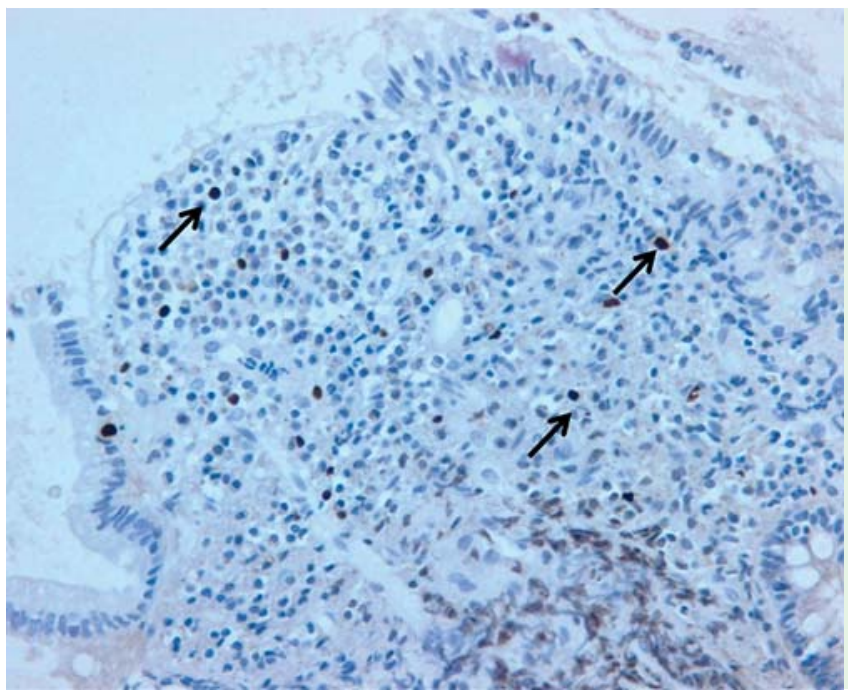

Fig.4 In situ hybridization of the smallintestinal mucosa. Epstein-Barr virus (EBV)-encoded RNA in situ hybridization revealed a marked increase in the number of EBV-infected cells in the small-intestinal mucosa (arrows).

together, a final diagnosis of small-intestinal EBV-associated T-cell lymphoproliferative disorder was made. Despite sequential treatment with cyclosporine and CHOP (cyclophosphamide, doxorubicin, vincristine, and prednisolone), the patient died in March 2010.

EBV-associated T-cell lymphoproliferative disorder is rare and has a poor prognosis, with a median survival of only a few months despite intensive chemotherapy $[1,2]$. In this case, proliferated $B$ cells activated by EBV-infected CD4+T cells may have induced diffuse villous atrophy by damaging the small-intestinal mucosal structure, and yielded clearly visible small-intestinal Peyer's patches by increasing the volume of the lymphoid follicles. It is often difficult to differentiate small-intestinal lymphoproliferative dis- orders from celiac disease, which also originates from activated $\mathrm{T}$ cells and often shows similar endoscopic findings [3-5]. This case suggested that to suspect EBV infection endoscopically followed by histological detection of EBV-encoded RNA is an efficient way to diagnose smallintestinal EBV-associated lymphoproliferative disorders.

\section{Acknowledgments \\ $\nabla$}

We are grateful to Tohru Tanizawa and Humie Saegusa, Department of Pathology, Chiba University Hospital.

Endoscopy_UCTN_Code_CCL_1AC_2AC

Competing interests: None
S. Sazuka ${ }^{1}$, Y. Takahashi ${ }^{1}$, T. Kawaguchi $^{2}$, T. Sato ${ }^{1}$, T. Nakagawa ${ }^{1}$, Y. Furuya ${ }^{1}$, M. Saito ${ }^{1}$, K. Saito ${ }^{1}$, T. Katsuno ${ }^{1}$, C. Nakaseko ${ }^{2}$, O. Yokosuka ${ }^{1}$

${ }^{1}$ Department of Gastroenterology and Hepatology, Chiba University Hospital, Chiba-shi, Japan

2 Department of Hematology, Chiba University Hospital, Chiba-shi, Japan

\section{References}

1 Rezk SA, Weiss LM. Epstein-Barr virus-associated lymphoproliferative disorders. Hum Pathol 2007; 38: $1293-1304$

2 Carbone A, Gloghini A, Dotti G. EBV-associated lymphoproliferative disorders: classification and treatment. Oncologist 2008; 13: 577-585

3 Tursi A, Brandimarte G, Giorgetti GM et al. Endoscopic features of celiac disease in adults and their correlation with age, histological damage, and clinical form of the disease. Endoscopy 2002; 34: 787-792

4 Olds G, McLoughlin R, O'Morian C et al. Celiac disease for the endoscopist. Gastrointest Endosc 2002; 56: 407-415

5 Dickey W. Endoscopic markers for celiac disease. Nat Clin Pract Gastroenterol Hepatol 2006; 3: 546-551

\section{Bibliography}

Dol http://dx.doi.org/

10.1055/s-0030-1257081

Endoscopy 2012; 44: E30-E31

(C) Georg Thieme Verlag KG

Stuttgart · New York

ISSN 0013-726X

\section{Corresponding author}

\section{T. Katsuno, MD}

Department of Medicine and Clinical Oncology

(K1)

Graduate School of Medicine

Chiba University, 1-8-1 Inohana

Chuo-ku, Chiba-shi

260-8670

Japan

Fax: +81432262088

katsuno@faculty.chiba-u.jp 